\title{
An Insight into the Role of Glycerol in Chitosan Films
}

\author{
S. Rivero ${ }^{1}$ - L. Damonte ${ }^{2}$ M. A. García ${ }^{1}$ - A. Pinotti ${ }^{1,3}$
}

Received: 23 June 2015 / Accepted: 21 December 2015

(C) Springer Science+Business Media New York 2016

\begin{abstract}
This work was focused on assessing the influence of the glycerol in chitosan matrices, analyzing the changes produced in the molecular mobility, mechanical, thermal, barrier and structural properties. The addition of glycerol in the matrix decreased the stress values, increasing the elasticity and water vapor permeability of the films, with a marked decrease in glass transition temperature; Detailed analyses of Fourier Transform IR Spectroscopy spectra supported the observed changes, especially in the spectral windows 1700 $1500 \mathrm{~cm}^{-1}$ revealing the modifications at molecular level caused by hydrogen bond interactions between chitosan and water in the presence of glycerol. Positron annihilation spectroscopic (PALS) measurements allowed determining the free volume assuming spherical holes as well as monitoring the structural changes in chitosan films caused by the addition of both, glycerol and water molecules. It was possible to infer that for unplasticized matrices, a sustained increase of the radius between 0.06 and 0.2 of $X_{\text {water }}$ was observed, followed by a plateau up to 0.35 . In the other case, with the addition of glycerol, there were two plateaus, the first between 0.25 and 0.37 of $X_{\text {water, }}$, and the second from 0.41 to 0.47 . For higher glycerol concentrations, the plasticizer would be mainly bounded to the chitosan pack more efficiently and the water present in the system would be predominantly free in the
\end{abstract}

S. Rivero

sandra_gmr@yahoo.com

1 Center for Research and Development in Food Cryotechnology (CCT-CONICET), 47 and 116, La Plata 1900, Argentina

2 Department of Physics, Faculty of Exact Sciences, UNLP, La Plata 1900, Argentina

3 Faculty of Engineering, UNLP, La Plata 1900, Argentina matrix causing its swelling. Findings on molecular mobility contributed to the understanding of the role of water and glycerol in the structural arrangement and its influence on film properties.

Keywords PALS $\cdot$ Plasticizer $\cdot$ Chitosan films $\cdot$ Molecular mobility · FTIR

\section{Introduction}

Packaging is a potential area for the application of chitosan films. This biopolymer is a hydrophilic and natural polymer derived from chitin by deacetylation, widely found in crustaceans and insects, the second most abundant biopolymer in nature after cellulose [1].

Considering the hydrophilic character of biodegradable films, water molecules can constitute a problem due to their strong plasticizer effects in films, modifying the physical properties of the material [2]. Furthermore, the addition of low molecular weight plasticizers to amorphous biopolymers increases the matrix free volume and the molecular mobility $[3,4]$.

Polyols such as glycerol contain hydrophilic groups, in which the water molecules interact with the macromolecules by means of hydrogen bonds, resulting in moisture absorption.

Several authors have addressed a parallelism between plasticizing effect and free volume but only a few have so far put the theory into experimental measures.

The free volume of amorphous materials or polymers is the volume unoccupied by the material's molecules. Plasticization is explained by the free volume theory as the increase in the intermolecular spaces of the polymeric matrix $[5,6]$. According to Roussenova et al. [7] it is essential to quantify the local free volume in a system since it plays an important 
role in phenomena such as self-diffusion, the diffusion of guest molecules and the glass transition temperature.

In order to highlight the interaction of chitosan with plasticizer molecules, the changes of the matrix induced by hydration at a molecular level should be considered. FTIR is often used with this purpose. Furthermore, positron annihilation lifetime spectroscopy (PALS) provides information on the size of free volume holes in an amorphous material, and thus on the plasticizer-induced structural changes of the polymers; hence the changes in local free volume observed may be related to the changes in the macroscopic bulk properties. The versatility of PALS for the study of polymers allows an integrated approach in conjunction with complementary techniques to establish composition-structure relationships at a molecular level.

References about film molecular mobility studied by PALS and structural changes associated with plasticizers analysis are scarce. In this way, this work was focused on assessing the influence of the glycerol in chitosan matrices, analyzing the changes produced in the molecular mobility, mechanical, thermal, barrier and structural properties.

\section{Materials and Methods}

\section{Reagents}

Commercial chitosan from crab shells with a minimum deacetylation degree of $75 \%$ was purchased from Sigma (St. Louis, MO, USA). Glycerol (analytical grade), used as plasticizer, was provided by J.T. Baker (Xalostoc, México).

\section{Film-Forming Solution Preparation}

Chitosan solution of $1.5 \%(w / w)$ was prepared by solubilization in $1.5 \%(v / v)$ acetic acid solution under stirring for 24 hours, as was described in a previous work [8]. A screening of plasticizer $(\mathrm{P})$ concentration was assayed in order to select the optimum; glycerol was added as plasticizer to chitosan solution. Tested concentrations were: $0.25,0.5,0.75$ and $1 \% \mathrm{~g}$ of glycerol / $100 \mathrm{ml}$ of chitosan solution $(w / v)$.

\section{Film Preparation}

Unplasticized and plasticized chitosan films were prepared by casting filmogenic solutions onto Petri dishes $(9 \mathrm{~cm}$ diameter) and dried at $37{ }^{\circ} \mathrm{C}$ in an oven until reaching constant weight. The obtained films were removed from the dishes and stored prior to the determinations of the structural, thermal, barrier and mechanical properties.

\section{Moisture Content}

Film moisture contents were determined by measuring their loss of weight, upon drying in an oven at $105 \pm 1{ }^{\circ} \mathrm{C}$ until reaching constant weight (dry sample weight). Samples were analyzed at least in triplicate and results were expressed in grams of water per $100 \mathrm{~g}$ of sample.

\section{Thickness}

Film thickness was determined using a coating thickness gauge Check Line DCN-900 (New York, USA) for nonconductive materials on non-ferrous substrates. The informed values correspond to the average of at least fifteen measurements at different positions for each specimen.

\section{Sorption Isotherm}

Sorption isotherms at $20^{\circ} \mathrm{C}$ for unplasticized films were studied according to the methodology described by Romano et al. [9]. Ten saturated salt solutions (slurries), generating constant $\mathrm{a}_{\mathrm{w}}$ atmospheres, were prepared for sample equilibration following the AOAC method 978.18 [10] and the described protocol by Demarchi, et al. [11]. In brief, samples were equilibrated in different atmospheres of saturated salts: $\mathrm{NaOH}, \mathrm{LiCl}$, $\mathrm{MgCl}_{2}, \mathrm{~K}_{2} \mathrm{CO}_{3}, \mathrm{NaBr}, \mathrm{NaCl}, \mathrm{KCl}$ and $\mathrm{BaCl}_{2}$ giving relative humidity $(\mathrm{RH})$ values of $8,11,33,43,59,75,85$ and $90.7 \%$, respectively. Chitosan films were previously dried and maintained in the presence of $\mathrm{P}_{2} \mathrm{O}_{5}$ for 15 days. All isotherms were determined in triplicate, using an individual flask for each sample. Thymol was added to prevent fungal growth throughout the storage period in flasks with the highest relative humidities. Film samples were weighed at regular intervals until reaching constant weight. After that, water activity was determined by the static gravimetric method. Equilibrium was assumed as variations in moisture content became less than $0.003 \mathrm{~g}_{\text {water }} / \mathrm{g}_{\mathrm{dm}}$. Additionally, the kinetics of water sorption by the chitosan films was also performed by the fast hygrometric method using Aqualab hygrometer (Decagon, USA). Measurements were performed in triplicate.

In the present study the GAB [12], Smith [13], Oswin, [14] and Chirife \& Iglesias [15] models were used for fitting the sorption data using Sigma Plot Software 10.0.

\section{Modulated Differential Scanning Calorimetry (MDSC)}

Thermal properties of films with and without plasticizer were determined using MDSC model Q100 controlled by a TA 5000 module (TA Instruments, New Castle, Delaware, USA), with a quench cooling accessory, under a $\mathrm{N}_{2}$ atmosphere $\left(20 \mathrm{ml} \mathrm{min}^{-1}\right)$, using a heating rate of $10{ }^{\circ} \mathrm{C} \mathrm{min}{ }^{-1}$ and a temperature modulation of $\pm 0.50^{\circ} \mathrm{C} / \mathrm{min}$. Film samples 
of 6-7 mg were weighed in aluminum pans and hermetically sealed; an empty pan was used as a reference.

Samples were analyzed between -90 and $200{ }^{\circ} \mathrm{C}$, at a heating rate of $10^{\circ} \mathrm{C} \mathrm{min}^{-1}$. After the first scan was completed, the sample was cooled until $-90^{\circ} \mathrm{C}$ and then a second scan was recorded. Glass transition temperature $\left(\mathrm{T}_{\mathrm{g}},{ }^{\circ} \mathrm{C}\right)$ was determined from the reversible signal using the Universal Analysis V1.7 F software (TA Instruments, New Castle, USA). All measurements were performed at least twice for each sample.

\section{Water Vapor Permeability}

Water vapor permeability (WVP) tests were conducted based on a modified ASTM [16] method E96 using a specially designed permeation cell that was maintained at $20{ }^{\circ} \mathrm{C}$ according to the procedure described by Rivero et al. [8]. After steadystate conditions were reached, eight measurements were performed over $8 \mathrm{~h}$. Each informed value corresponded at least to four determinations.

\section{Dynamic Mechanical Analysis (DMA)}

DMA assays were conducted in a dynamic-mechanical thermal equipment Q800 (TA Instruments, New Castle, USA) using a clamp tension with a liquid $\mathrm{N}_{2}$ cooling system as described in a previous work [17]. Multi-frequency sweeps $(5,10$ and $15 \mathrm{~Hz})$ at a fixed amplitude $(7 \mu \mathrm{m})$ from -90 to $200{ }^{\circ} \mathrm{C}$ at $5{ }^{\circ} \mathrm{C} \min ^{-1}$ were carried out, with an isotherm of $15 \mathrm{~min}$ at $-90{ }^{\circ} \mathrm{C}$. The equilibrated film samples were coated with silicone grease to limit water exchange with the external atmosphere during measurements. Similar procedure was described by Cuq et al. [18].

\section{Tensile Stress-Strain}

Probes of $6 \mathrm{~mm} \times 30 \mathrm{~mm}$ were used to analyze the tensile stress-strain behavior of the films with and without plasticizer through the aforementioned DMA equipment, by using tension clamps. For quasi-static test in uniaxial condition, a preload force of $1 \mathrm{~N}$ and a constant force ramp rate of $0.3 \mathrm{~N} \mathrm{~min}^{-1}$ were applied to record the stress-strain curves until rupture from film sample strips or up to $18 \mathrm{~N}$. Tests were carried out at $25^{\circ} \mathrm{C}$. In order to calculate the elastic modulus at large deformations $\left(\mathrm{E}_{\mathrm{C}}\right)$, stress-strain curves were fitted to equation (1) [17]:

$\sigma_{V}=E_{C} \varepsilon_{V} e^{-\varepsilon_{V} K}$

where,

$\varepsilon_{\mathrm{v}}$ and $\sigma_{\mathrm{v}}$ are the true strain and the true stress, respectively; $\mathrm{E}_{\mathrm{C}}$ is the elastic modulus; $\mathrm{K}$ is a constant and have to be regarded as fitting parameter. Samples were analyzed at least in triplicate.

\section{FT-IR Spectroscopy}

The Fourier transform infrared (FT-IR) spectra of the films were recorded in an IR spectrometer (Nicolet, iS10 Thermo Scientific, Madison, USA) in the wavenumber range 4000 $400 \mathrm{~cm}^{-1}$ by accumulation of 64 scans at $4 \mathrm{~cm}^{-1}$ resolution. Data were analyzed by using the software Omnic 8 (Thermo Scientific, Madison, USA). The spectral deconvolution of the data was performed using curve fitting algorithms within the region $1700-1500 \mathrm{~cm}^{-1}$. Inverted second derivative spectra were used to estimate the number, position and relative contribution of individual elements composing of Amide I and Amide II. The software iterated the curve-fitting process by adjusting the peak high and width to achieve the best Gaussian-shaped curves that fit the original spectrum. In order to analyze the individual contribution of water and glycerol to plasticizing of matrices, samples with and without glycerol were prepared and equilibrated in different atmospheres of saturated salts as it was described in 2.3.3 section.

\section{Positron Annihilation Lifetimes Spectroscopy (PALS)}

PALS experiments proceed by injecting a positron into the material being tested and measuring the length of time until that positron annihilates with one of the material's electrons, producing $\gamma$-rays. Measurements were done at room temperature in a conventional fast-fast coincidence system with two plastic detectors. The time resolution (full-width-at-half-maximum, FWHM) was 260 ps and $3 \times 106$ counts were accumulated for each spectrum. The radioactive source, ${ }^{22} \mathrm{NaCl}$ $(10 \mu \mathrm{Ci})$, was deposited onto a kapton foil $\left(1.42 \mathrm{~g} \mathrm{~cm}^{-3}\right)$ and sandwiched between two sample specimens (chitosan films equilibrated at different relative humidities or matrices containing glycerol as plasticizer). The source contribution (17\% of 386 ps for the annihilation in kapton foil and $1 \%$ of $2.0 \mathrm{~ns}$ ) and the response function were evaluated from a reference sample (Ni metal) using the RESOLUTION code $[19,20]$. According to the common interpretation for PALS measurements in polymers, PALS spectra were deconvoluted into three lifetime components using the LT program, with an adequate source correction.

From the analysis, two discrete lifetimes and a continuous one corresponding to the long-lived component were obtained. This longest lifetime gives the ortho-positronium (o-Ps) lifetime component represented by the continuous distribution $\xi\left(1 / \tau_{3}\right)$. Positron lifetime spectra were also analyzed using the POSITRONFIT program giving three discrete lifetime components $\left(\tau_{1}, \tau_{2}\right.$ and $\tau_{3}$, respectively). The results obtained showed a very good agreement with those obtained from the decomposition of the PALS spectra using the LT program. As mentioned above, in the last series of decompositions a discrete lifetime component for the o-Ps component $\left(\tau_{3}\right)$ was 
considered. Measurements were carried out at least in duplicates.

\section{Statistical Analysis}

Systat-software (SYSTAT, Inc., Evanston, IL, USA) version 10.0 was used for all statistical analysis. Analysis of variance (ANOVA), linear regressions and Fisher LSD mean comparison test were applied. The significance levels used was 0.05 .

\section{Results and Discussion}

\section{Barrier and Mechanical Properties}

Chitosan films exhibited a water vapor permeability value of $1.0810^{-10} \mathrm{~g} \mathrm{~m}^{-1} \mathrm{~s}^{-1} \mathrm{~Pa}^{-1}$, which was lower than those reported for other biodegradable films based on protein soy and zein [21], corn starch [22] and cassava starch reinforced with natural fibrous filler [23]. However, the WVP values were higher than those obtained for methylcellulose [9] and kefiran films [24].

Table 1 shows the effect of the plasticizer addition on barrier properties. The WVP values of $\mathrm{CH}$ plasticized films significantly increased $(P<0.05)$ for the formulations with glycerol concentrations higher than $0.25 \%$. Cerqueira et al. [6] found a similar trend and attributed the increase in the permeability to the plasticizer effect of glycerol, which tends to reduce the density of packaging of polymeric chains, increasing the free volume matrix.

Although glycerol efficiency as plasticizer is determined by its low molecular weight, its high capacity to interact with water facilitates the solubilization and permeation through the film.

Figure 1 shows the stress- strain curves of the films. Unplasticized chitosan matrix presented a typical behavior of rigid materials. With the addition of $0.5 \%$ of glycerol, the matrix characteristics were slightly modified toward a ductile material, obtaining higher values of relative deformation.
However, the most remarkable changes occurred for concentrations greater than $0.5 \%$.

The glycerol used as a plasticizer did not undergo a release from the matrix irrespective of the concentration used. This result was evidenced by SEM observation (data not shown). These findings indicate a good miscibility between the matrix components and they are in agreement with the assumption of a clustering model at high glycerol concentrations, which was argued by Quijada-Garrido and coworkers [25]. It consists of a two-step mechanism, a first one in which the solvent is sorbed by means of hydrogen bonds on polymer-specific sites such as $-\mathrm{NH}_{2}$ or as $-\mathrm{NH}_{3}^{+}{ }_{3}^{-} \mathrm{OOC}-\mathrm{CH}$ (chitosonium acetate), $-\mathrm{CH}_{2} \mathrm{OH}$, restricting the motion of these glycerol molecules, and a second step in which glycerol molecules also form hydrogen bonds among them giving place to a clustering effect [26].

In Fig. 1 two well defined mechanical patterns can be observed. A more flexible material with higher values of $\varepsilon_{\mathrm{v}}$ corresponded to the highest glycerol concentrations $(0.75$ and $1 \%)$. The parameters that allowed characterizing the elastic zone of the curves were estimated from the equation (1); Table insert in Fig. 1 shows the $\mathrm{E}_{\mathrm{c}}$ estimated values. $\mathrm{CH}$ films presented the highest values of $E_{c}$, demonstrating the greatest strength of the material, while in the case of plasticized films the values decreased whereas the glycerol concentration increased (Table insert in Fig. 1). In comparison with other biodegradable materials, such as gellan matrices studied by León et al. [27], the $\mathrm{E}_{\mathrm{c}}$ values obtained for $\mathrm{CH}$ films were higher.

\section{Glass Transition Temperature Studied by MDSC and DMA}

The $T_{g}$ of chitosan-based films has been studied by several authors, who detected it in a wide range of temperatures [3, 27]. As expected, the higher glycerol concentration, the higher film water content, the lower $T_{g}$ values, as can be observed in Table 2.

Table 1 Effect of glycerol on the thickness, moisture content, water vapor permeability and thermal properties of chitosan film

\begin{tabular}{llllll}
\hline Glycerol concentration & & Thickness $(\mu \mathrm{m})$ & Moisture content $(\mathrm{g} / 100 \mathrm{~g}$ films $)$ & WVP $\times 10^{10}\left(\mathrm{~g} \mathrm{sec}^{-1} \mathrm{~m}^{-1} \mathrm{~Pa}^{-1}\right)$ & Experimental $^{*} \mathrm{~T}_{\mathrm{g}}$ \\
\hline$(\% w / v)$ & $(\% w / w)$ & & & \\
\hline 0 & 0 & $42.5(1.5)^{\mathrm{a}}$ & $17.1(0.80)^{\mathrm{a}}$ & $1.08(0.042)^{\mathrm{a}}$ & $96.0(3.32)^{\mathrm{a}}$ \\
0.25 & 16.67 & $45.9(1.6)^{\mathrm{b}}$ & $25.56(0.57)^{\mathrm{b}}$ & $1.02(0.044)^{\mathrm{a}}$ & $93.6(2.73)^{\mathrm{a}}$ \\
0.5 & 33.33 & $50.7(1.7)^{\mathrm{c}}$ & $37.67(1.06)^{\mathrm{c}}$ & $1.24(0.012)^{\mathrm{b}}$ & $60.7(2.9)^{\mathrm{b}}$ \\
0.75 & 50 & $54.2(1.6)^{\mathrm{d}}$ & $41.49(1.43)^{\mathrm{d}}$ & $1.36(0.030)^{\mathrm{c}}$ & $42.6(2.4)^{\mathrm{c}}$ \\
1.0 & 66.67 & $59.2(2.7)^{\mathrm{e}}$ & $46.77(1.15)^{\mathrm{e}}$ & $1.61(0.041)^{\mathrm{d}}$ & $20.8(0.1)^{\mathrm{d}}$ \\
\hline
\end{tabular}

* $\mathrm{T}_{\mathrm{g}}$ values obtained by MDSC

Different letters in the same column indicate significant differences between the samples $(p<0.05)$ 
Fig. 1 Tensile stress strain behavior of $\mathrm{CH}$ films as a function of glycerol concentration. Continuous lines indicate the fit of equation (1) to data. The Table insert shows the $\mathrm{E}_{\mathrm{c}}$ values estimated from the model

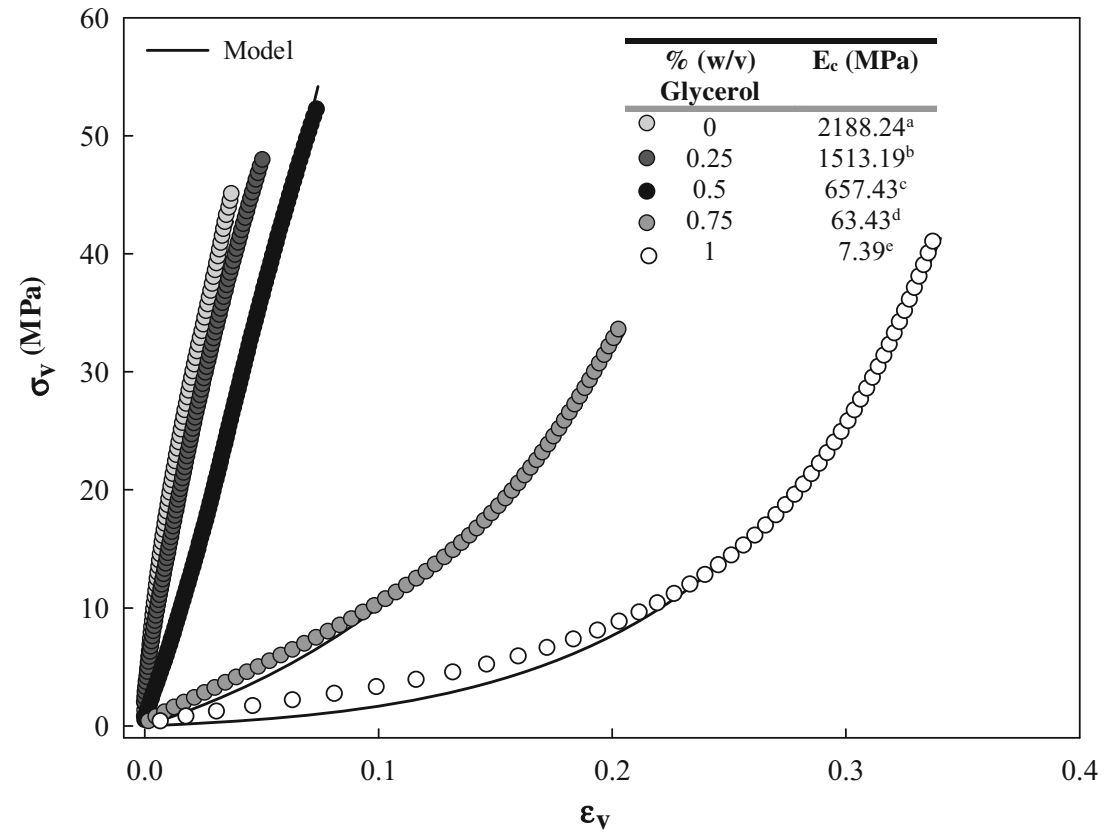

Dynamic mechanical pattern of $\mathrm{CH}$ films showed two relaxations, $\beta$ and $\alpha$ with increasing temperature. The $\beta$ relaxation was located around $-10^{\circ} \mathrm{C}$. Neto et al. [28] and Mucha and Pawlak [29] reported this event at around -20 to $-10{ }^{\circ} \mathrm{C}$. The $\alpha$-relaxation coincides with the dynamic glass transition temperature $\left(\mathrm{T}_{\mathrm{g}}\right)$, irrespective of the frequency tested. In this case it was found at $100{ }^{\circ} \mathrm{C}$ for $\mathrm{CH}$ films (Fig. 2), this value being similar to that obtained by MDSC technique $\left(96^{\circ} \mathrm{C}\right)$.

Table 2 Sorption isotherm model constants and coefficient of regression $\mathrm{R}^{2}$ values for chitosan films

\begin{tabular}{lllll}
\hline Model & \multicolumn{2}{l}{ Fitting constants ${ }^{* *}$} & \\
\hline GAB & $\mathrm{X}_{\mathrm{m}}$ & $\mathrm{C}$ & $\mathrm{K}$ & $\mathrm{R}^{2}$ \\
$\mathrm{~A}^{*}$ & 0.105 & $2.44 \mathrm{E}+05$ & 0.90 & 0.980 \\
$\mathrm{~B}^{*}$ & 0.108 & 11.06 & 0.924 & 0.991 \\
Smith & $\mathrm{b} 1$ & $\mathrm{~b} 2$ & & $\mathrm{R}^{2}$ \\
A & 0.189 & 0.084 & & 0.955 \\
B & 0.250 & 0.015 & & 0.978 \\
Oswin & $\mathrm{b} 1$ & $\mathrm{~b} 2$ & & $\mathrm{R}^{2}$ \\
A & 0.416 & 0.215 & & 0.950 \\
B & 0.564 & 0.185 & & 0988 \\
Chirife and Iglesias & $\mathrm{b} 1$ & $\mathrm{~b} 2$ & & $\mathrm{R}^{2}$ \\
A & 0.049 & 0.137 & & 0.984 \\
B & 0.065 & 0.116 & & 0.972 \\
\hline
\end{tabular}

* Parameters obtained from fitting the data obtained by the gravimetric method (A) and the hygrometric method (B) in the range of water activity of $0.1-0.9$

${ }^{* *}$ Fitting parameters are defined by GAB [12], Smith [13], Oswin [14] and Chirife \& Iglesias [15] models
DMA allowed analyzing the effect of glycerol addition on chitosan matrix. In the case of $\mathrm{CH}$ films with $0.5 \%$ of glycerol $(w / v)$ the $\beta$ relaxation showed a maximum at $-20{ }^{\circ} \mathrm{C}$, which represented a significant displacement with respect to the value found for the control film $\left(-10^{\circ} \mathrm{C}\right)$. This shift was attributed to the movements due to the interaction of chitosan with glycerol molecules through hydrogen bonds with the groups $\mathrm{NH}_{2},-\mathrm{CH}_{2} \mathrm{OH},-\mathrm{NH}-\mathrm{CO}-\mathrm{CH}_{3}$ [25]. Furthermore, Domjan et al. [30] studied the dynamic and structural changes in a chitosan matrix with glycerol and they found that the plasticizer interact with acetamide groups of chitosan, decreasing its mobility and prevents interactions between adjacent chains of the polymer. The addition of $0.25 \%$ of glycerol did not produce significant $(P>0.05)$ changes in the obtained spectra. However, it must be emphasized that the addition of $0.5 \%$ plasticizer shifted $\mathrm{T}_{\mathrm{g}}$ value to a temperature close to $80{ }^{\circ} \mathrm{C}$ (Fig. 2) and increased the $\alpha$-relaxation intensity. For higher plasticizer concentrations the determination of the $T_{g}$ by using this technique was not possible under the tested conditions. The E' values fell below the equipment sensitivity limit (Fig. 2), without allow detecting the maximum in $\tan \delta$ curve.

\section{Behavior of CH Films Conditioned at Different Relative Humidities}

Considering the hydrophilic character of biodegradable films, the study of the water sorption in the chitosan film and the structural relations between the polymer matrix and the water were performed. In order to conduct a theoretical interpretation of sorption isotherms, mathematical models based on empirical and theoretical approaches were applied. 
Fig. 2 Dynamic mechanical spectra showing the tangent of phase angle $(\tan \delta)$ of chitosan films with different glycerol concentrations

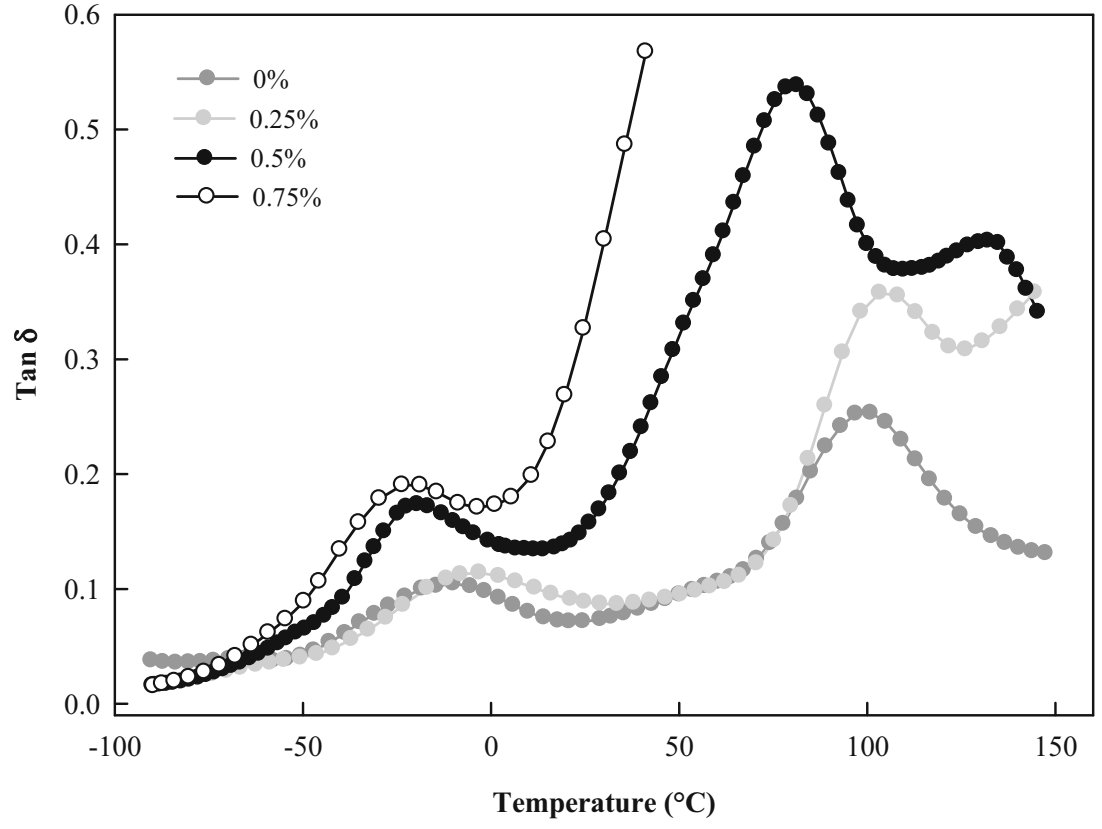

The models describe the relationship between the equilibrium moisture content and $\mathrm{a}_{\mathrm{w}}$. Experimental data obtained for both methods (gravimetric and hygrometric) were fitted mathematically with the models presented in Table 2.

Figure 3 a depicts sorption isotherms obtained for $\mathrm{CH}$ films. The experimental data showed correspond to both, hygrometric and gravimetric methods. In this latter case, it was considered that $\mathrm{a}_{\mathrm{w}}$ could be estimated from the relative humidity of the surrounding atmosphere ( $\mathrm{RH})$, assuming that thermodynamic equilibrium had been reached [11]. According to Fennema [31] and Slade and Levine [32] the water activity is an equilibrium concept derivative of the chemical potential of a system. Given the nature of this condition, it is unlikely to reach, and thus it is convenient to measure $a_{w}$ instead of assuming that this equilibrium has been reached.

The sorption isotherms of $\mathrm{CH}$ films showed a fast adsorption of water at low RH values. This fact allows inferring the presence of strongly bound water and suggests that the occurrence of the three types of sorption, both strongly and weakly adsorbed monolayer as well as the multilayer. Similar results were reported by Yakimets et al., [33]. The GAB model demonstrated the greatest capability to predict the total water sorption $\left(\mathrm{R}^{2}>0.99\right)$.

The insert of Fig. 3a shows the correlation obtained between $\mathrm{a}_{\mathrm{w}}$ of $\mathrm{CH}$ films and the values predicted by the GAB model

On the other hand, samples equilibrated at different relative humidities exhibited broad endothermic transitions in the temperature range from 100 to $160^{\circ} \mathrm{C}$. As expected, the total area of endothermic peak increased with the film moisture content, showing a correlation between the enthalpy and the moisture content (Fig. 3b).

\section{FTIR of Chitosan Films}

Considering the individual contribution of water and glycerol to the plasticizing of the matrices and the changes induced by hydration at structural and molecular levels, FTIR spectra were analyzed. Samples with and without glycerol were studied by focusing on spectral windows that reveal hydrogen bond interactions.

The individual effects of both glycerol and water as plasticizer were studied through the deconvolution technique of the Amide bands into individual components contributing to the overall envelopes within region $1700-1500 \mathrm{~cm}^{-1}$.

Figure 4a shows the IR spectra of chitosan films at different RH in the $1700-1500 \mathrm{~cm}^{-1}$ range. This window corresponds to the mode of bending of the water molecules present in the polymer matrix [27], shifting slightly toward higher wavenumbers as the relative humidity increased.

Considering the chitosan structure, water molecules can be bound by two polar groups, hydroxyl and amine present in this polymer [28]. The presence of water in IR absorption affects the $\mathrm{CH}-$ stretching band of chitosan as well as the Amide I and Amide II bands situated at 1650 and $1556 \mathrm{~cm}^{-1}$, respectively. Spectra deconvolution results can be visualized in Fig. 4a. The use of this method improved the resolution of the band at $1650 \mathrm{~cm}^{-1}$ which is unfolded in two peaks located at 1658 and $1635 \mathrm{~cm}^{-1}$ related to water. This band widened with the moisture content, until reaching a plateau for the films conditioned at relative humidity higher than $75 \%$. According to Laporta et al. [34], this fact would be due to the increase in the hydrogen bond strength. These findings are analogous to those found by Yakimets et al. [33]. 
Fig. 3 a) Sorption isotherm for chitosan films obtained from the experimental values and predicted by the GAB model. Experimental data were obtained measuring the moisture content using both the hygrometric method $(\circ)$ and the gravimetric method $(\bullet)$; b) correlation between the enthalpy values obtained by MDSC and the moisture content of the samples
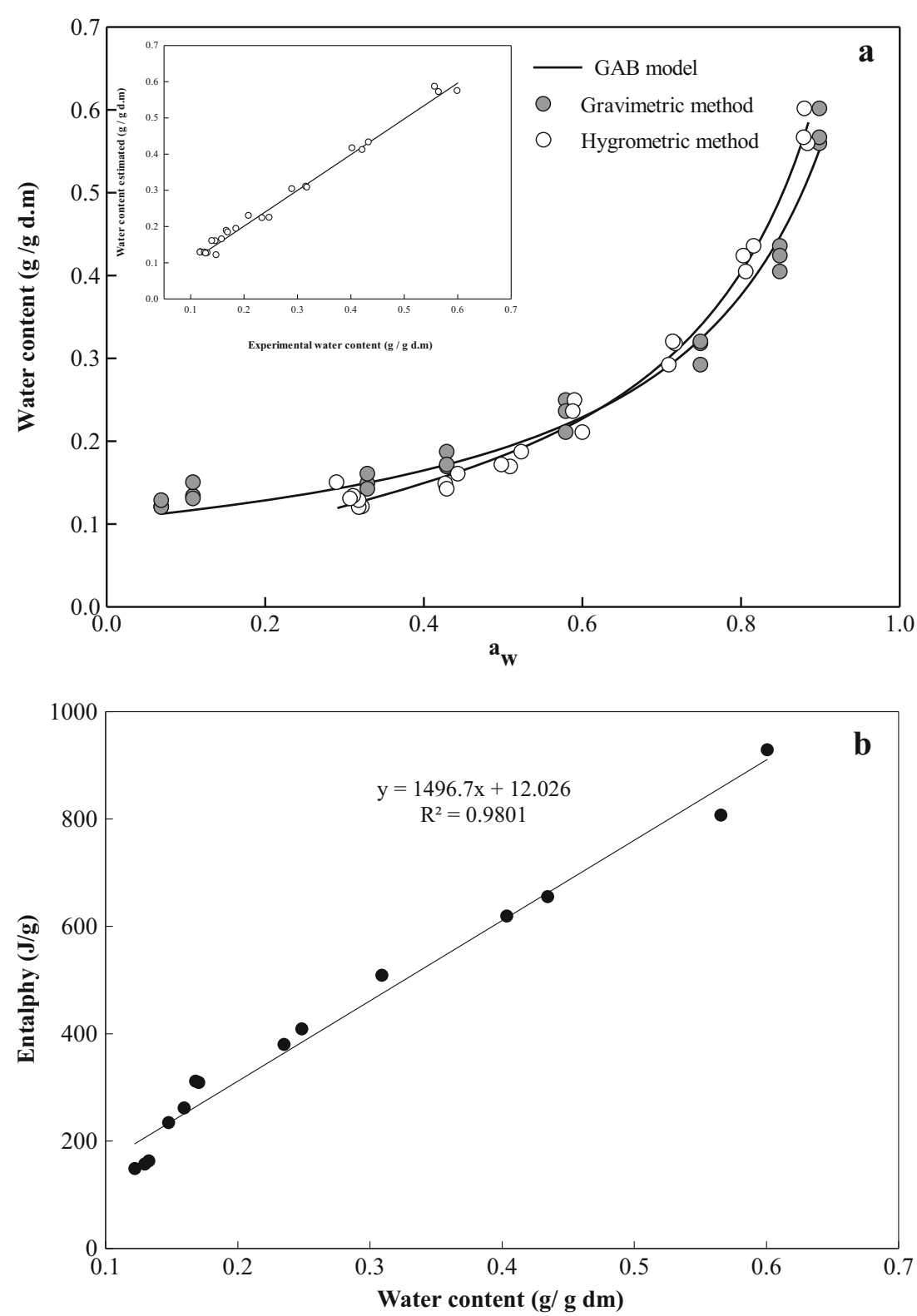

The band corresponding to Amide II arises from vibrations, which are mainly due to N-H bending, and is therefore sensitive to hydrogen bond. The deconvolution of this band showed a single peak after iterative curve-fitting procedure.

In the case of chitosan plasticized films, as can be seen in Fig. $4 \mathrm{~b}$, the spectra deconvolution of the band corresponding to Amide I was also unfolded in two peaks located at 1658 and $1635 \mathrm{~cm}^{-1}$ related to water. In addition, the Amide II deconvolution showed the contribution of two components at 1559 and $1591 \mathrm{~cm}^{-1}$ with the addition of $0.25 \%$ of glycerol. This latter underwent a shift to higher wavenumbers (1565 and $1597 \mathrm{~cm}^{-1}$, respectively) with increasing glycerol concentration.

On the other hand, the appearance of a shoulder in the region $1460-1455 \mathrm{~cm}^{-1}$ for plasticized chitosan films, attributed to the stretching of the $\mathrm{CH}_{2}$ group, was becoming more pronounced with increasing glycerol concentration (Fig. 4c). Wilhelm et al. [35] pointed out that this signal indicates that the plasticizer added was chemically bonded to the polymer chains, demonstrating that an internal plasticization of the $\mathrm{CH}$ matrix took place.

\section{PALS Analysis}

The local free volume consists of a large number of subnanometre-sized free volume elements, commonly referred to as holes. The mean size of the holes forming the free volume can be roughly estimated by means of a simple quantum mechanical model. o-Ps in a hole is approximated to a particle in a spherical potential well with radius $\mathrm{R}_{0}$. It is assumed that 
Fig. 4 a) Unresolved FTIR spectra and curve fitting analysis in the Amide I and Amide II regions of: $\mathrm{CH}$ films conditioned at different relative humidities; b) FTIR spectra and curve fitting analysis in the Amide I and Amide II regions of $\mathrm{CH}$ plasticized with glycerol. Experimental data (dotted lines) and individual Gaussian components (solid lines) are shown; c) FTIR spectra of $\mathrm{CH}$ films with different glycerol concentrations in the wavenumber $1480-1300 \mathrm{~cm}^{-1}$
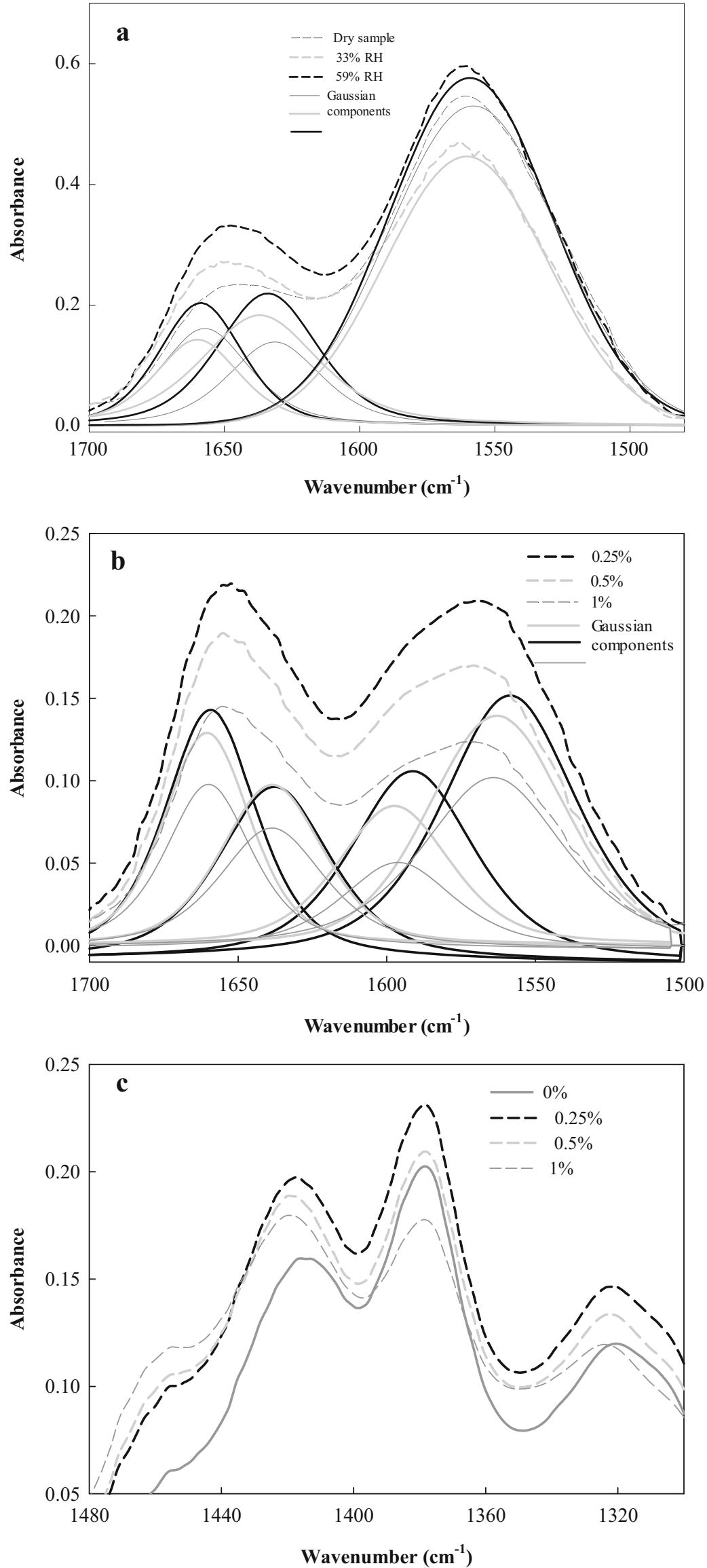
an electronic layer forming a thickness $\delta \mathrm{R}$ is present on the walls of the hole, whose effective radius is consequently reduced to $\mathrm{R}=\mathrm{R}_{0}-\delta \mathrm{R}$. As a consequence, the following semi-empirical equation (2) relating $\mathrm{R}(\mathrm{nm})$ and $\tau 3$ (ns) is usually used:

$\tau=0.5\left[1-\frac{R}{R+1.66}+\frac{1}{2 \pi} \sin \left(\frac{2 \pi R}{R+1.66}\right)\right]^{-1}$

The first and second lifetime components take into account positron annihilation in matrix regions with different electron densities. The first lifetime $\tau_{1}$ also includes $p$-Ps annihilation $\left(\tau_{\mathrm{p}-\mathrm{Ps}}=125 \mathrm{ps}\right)$, while $\tau_{2}$ accounts for free-positron annihilation $\left(\tau_{\text {kapton }}=386 \mathrm{ps}\right)$.

The long-lived component $\left(\tau_{3}\right)$ is the relevant one for void determination, since it corresponds to o-Ps annihilation in the void space, and according to the TaoEldrup model it correlates with the cavity dimensions through equation (2).

Figure 5 shows the water fraction $\left(\mathrm{X}_{\mathrm{water}}\right)$ in each system and its effect on the average hole size and glass transition temperature for both unplasticized samples equilibrated at different relative humidities and chitosan films plasticized with glycerol, in order to elucidate the dependence of molecular packing of chitosan matrices with regard to water and glycerol content.

By observing Fig. 5, it is possible to infer the existence of an inverse relationship between the glass transition temperature and the water fraction in both plasticized and unplasticized films.

Upon the conditions studied, the $T_{g}$ of the both systems conditioned at different relative humidities as well as plasticized with glycerol, remained above room temperature. Hence, the molecular organization corresponded to an amorphous glass state.

As the water content increased, whilst the matrices are still in the glassy state, an increase in the radius and consequently in volume as a function of water content was observed. It has been shown that water molecules have a significant diffusional mobility even in the glassy state, thus allowing them to plasticize their local environment, causing an increase in volume. The increase of the amount of water from 0.06 to 0.35 caused a decrease of the glass transition temperature of the unplasticized films from 126 to $54{ }^{\circ} \mathrm{C}$. Meanwhile, in the plasticized matrix $\mathrm{T}_{\mathrm{g}} \mathrm{s}$ underwent a shift from $96{ }^{\circ} \mathrm{C}$ to $21{ }^{\circ} \mathrm{C}$ for a water fraction of 0.17 and 0.47 , respectively.

For the water fraction common to both types of matrices (ranging between 0.18 and 0.38 ), $\mathrm{T}_{\mathrm{g}}$ values of plasticized films remained above those obtained for unplasticized films.

On the other hand, following the evolution of the hole radius with the water fraction was possible to draw a parallelism between both types of films. For unplasticized matrices, a sustained increase of the radius between 0.06 and 0.2 of $X_{\text {water }}$ was observed, followed by a plateau up to 0.35 . In the other case, with the addition of glycerol, there were two plateaus, the first between 0.25 and 0.37 of $X_{w a t e r}$, and the second from 0.41 to 0.47 . Consequently, when the matrix behavior was closer to the rubbery state, the higher the water fraction was, the smaller the difference in both radius and $T_{g}$ values were (Fig. 5).

On the assumption that water activity and glycerol concentration increase further in the same pattern, the matrices would reach the rubbery state and the difference in hole radius between the various matrix compositions would become even smaller, in accordance with the results of Roussenova et al. [36].

According to Roussenova et al. [37], at very low water content, the addition of glycerol is also likely to interfere with the hydrogen bonding between the polymeric chains, thus allowing them to pack more efficiently. In this stage of the glassy state, a non-linear decrease in volume was observed as
Fig. 5 Relationships between radius $(\AA)$, glass transition temperatures $\left(\mathrm{T}_{\mathrm{g}}\right)$ and water content $\left(\mathrm{X}_{\text {water }}\right)$. Dash dot lines just connect two consecutive experimental points. This line is uncertain because no points in between were analyzed

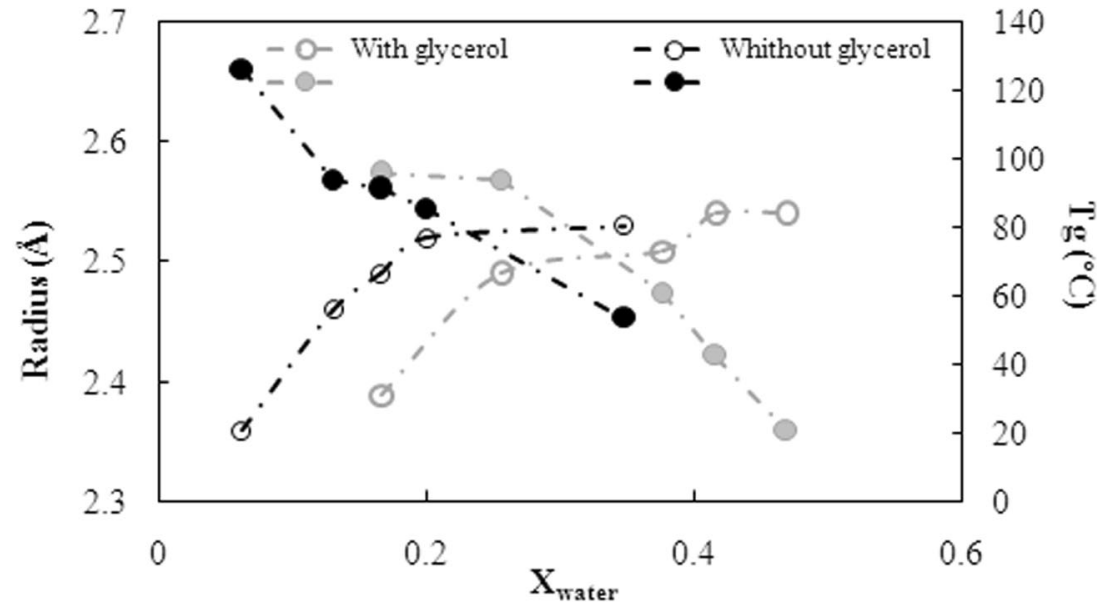


a function of increasing glycerol content, indicative of a nonideal packing behavior. Consequently, glycerol acts as a packing enhancer for the matrices causing systematic reductions in the average hole size.

In our case, over the entire concentration range studied, the initial increase in the average hole radius of the chitosan matrices upon sorption of water indicated that water acts as a plasticizer, thereby increasing the separation between the polymeric chains.

At fixed points of $\mathrm{X}_{\mathrm{water}}$ such as 0.17 and 0.47 corresponded reductions by 4 and $0.4 \%$ in the radius values after the addition of glycerol into the chitosan matrix, indicating that glycerol not only acts as a plasticizer but also as a packing enhancer. Moreover, the addition of glycerol caused, at $X_{\text {water }}$ fixed, a minor decrease of $\mathrm{T}_{\mathrm{g}}$ than that caused by the sole presence of water. However, near the rubbery state, $T_{g}$ decreased with a more abrupt slope until reaching room temperature.

Initially, upon hydration, water molecules bind to the polar side groups of the chitosan polymeric chains, which alter the hydrogen bonding interactions between them. As the water content increases further, water molecules become accommodated between the polymeric chains being able to cause further swelling of the matrix. Similar explanations were reported by Roussenova et al. [7] and Yakimets et al. [33].

In the same way as the radius-water fraction curves, the oPs intensity measured for unplasticized chitosan films conditioned was higher than the o-Ps measured for the plasticized chitosan matrices with glycerol. Similar results were found by Pintye-Hódi et al. [38] working on methylcellulose films with the addition of PEG.

\section{Conclusions}

The presence of glycerol in the matrix decreased material resistance, increasing the elasticity and water vapor permeability of the films, with a marked decrease in glass transition temperature. Detailed analyses of FTIR spectra supported the observed changes, especially in the spectral windows 1700 $1500 \mathrm{~cm}^{-1}$ revealing the modifications at molecular level caused by hydrogen bond interactions between chitosan and water in the presence of glycerol.

Positron annihilation spectroscopic measurements allowed determining free volume assuming spherical holes as well as monitoring the structural changes in chitosan films caused by the addition of both, glycerol and water molecules. The differences observed in the radius associated to free volume could be attributed to hydrogen bond interactions waterpolymer and glycerol-polymer and the differences in molecular sizes of water and plasticizer.

Results showed different behaviors of water and glycerol on chitosan matrix. When both components were simultaneously present, the active sites of polymer would be preferably occupied by glycerol while water molecules would interact with the remaining sites. With higher glycerol concentrations the free water content may increase in the polymeric matrix.

Findings on molecular mobility contributed to the understanding of the role of water and glycerol in the structural arrangement and its influence on film properties.

Acknowledgments This work was supported by the Argentinean Agency for the Scientific and Technological Promotion (ANPCyT) (Project PICT/2012/0415) and the Argentinean National Research Council (CONICET) (PIP 2013-0109). Authors acknowledge Ing.Javier Lecot and Daniel Russo for technical assistance.

\section{References}

1. M.N.V. Ravi Kumar, R.A.A. Muzzarelli, C. Muzzarelli, H. Sashiwa, A.J. Domb, Chitosan chemistry and pharmaceutical perspectives. Chem. Rev. 104, 6017-6084 (2004)

2. P. Bergo, I.C.F. Moraes, P.J.A. Sobral, Effects of different moisture contents on physical properties of PVA-gelatin films. Food Biophys. 7, 354-361 (2012)

3. A. Lazaridou, C.G. Biliaderis, Thermophysical properties of chitosan, chitosan-starch and chitosan-pullulan films near the glass transition. Carbohydr. Polym. 48(2), 179-190 (2002)

4. J.F. Fundo, R. Fernandes, P.M. Almeida, A. Carvalho, G. Feio, C.L.M. Silva, M.A.C. Quintas, Molecular mobility, composition and structure analysis in glycerol plasticised chitosan films. Food Chem. 144, 2-8 (2014)

5. R. Sothornvit, J.M. Krochta, Plasticizers in edible films and coatings innovations", in Innovations in Food Packaging, ed. by J.H. Han (Elsevier, Amsterdam, 2005), pp. 403-428

6. M.A. Cerqueira, B.W.S. Souza, J.A. Teixeira, A.A. Vicente, Effect of glycerol and corn oil on physicochemical properties of polysaccharide films e a comparative study. Food Hydrocolloid. 27, 175-184 (2012)

7. M. Roussenova, J. Enrione, P. Diaz-Calderon, A.J. Taylor, J. Ubbink, M.A. Alam, A nanostructural investigation of glassy gelatin oligomers: molecular organization and interactions with low molecular weight diluents. New J. Phys. 14(3), 1-18 (2012)

8. S. Rivero, M.A. García, A. Pinotti, Crosslinking capacity of tannic acid in plasticized chitosan films. Carbohydr. Polym. 82, 270-276 (2010)

9. N. Romano, M.J. Tavera-Quiroz, N. Bertola, P. Mobili, A. Pinotti, A. Gómez-Zavaglia, Edible methylcellulose-based films containing fructo-oligosaccharides as vehicles for lactic acid bacteria. Food Res. Int. 64, 560-566 (2014)

10. AOAC (Association of Official Analytical Chemists), Official Methods of Analysis, 16th edn. (AOAC International, Gaithersburg, 1998)

11. S.M. Demarchi, N.A. Quintero-Ruiz, A. De Michelis, S.A. Giner, Sorption characteristics of rosehip, apple and tomato pulp formulations as determined by gravimetric and hygrometric methods. LWT Food Sci. Technol. 52, 21-26 (2013)

12. H. Bizot, Using the GAB model to construct sorption isotherms, in Physical Properties of Foods, ed. by R. Jowitt, F. Escher, B. Hallstrom, H.F.T. Meffert, W.E.L. Spiess, G. Vos (Applied Science Publishers, London, 1983), pp. 43-54 
13. S.E. Smith, The absorption of water by high polymers. J. Am. Chem. Soc. 69, 646-651 (1947)

14. C.R. Oswin, Kinetics of package life. III. The isotherm. J. Soc. Chem. Ind. 65, 419-421 (1946)

15. J. Chirife, H.A. Iglesias, Equations for fitting water sorption isotherms of food: part 1. a review. J. Food Technol. 13, 159-174 (1978)

16. ASTM, Standard Test Methods for Water Vapor Transmission of Material, E96-95, Annual Book of ASTM (American Society for Testing and Materials, Philadelphia, 1995)

17. S. Rivero, L. Giannuzzi, M.A. García, A. Pinotti, Controlled delivery of propionic acid from chitosan films for pastry dough conservation. J. Food Eng. 116, 524-531 (2013)

18. B. Cuq, N. Gontard, S. Guilbert, Thermal properties of fish myofibrillar protein-based films as affected by moisture content. Polymer 38(10), 2399-2405 (1997)

19. P. Kirkegaard, M. Eldrup, A versatile program for analyzing positron lifetime stectra. Comput. Phys. Commun. 3, 240-255 (1972)

20. P. Kirkegaard, M. Eldrup, Positronfit extended: a new version of a program for analyzing positron lifetime spectra. Comput. Phys. Commun. 7, 401-409 (1974)

21. M. Lacroix, K. Cooksey, Edible films and coating from animalorigin proteins, In: Elsevier Ltd (Ed.). Innovations in Food Packaging, pp. 301-312, Chapter 18, (2005).

22. O. López, M.A. García, N. Zaritzky, Film forming capacity of chemically modified corn starches. Carbohydr. Polym. 73, 573581 (2008)

23. F. Versino, M.A. García, Cassava (Manihot esculenta) starch films reinforced with natural fibrous filler. Ind. Crops Prod. 58, 305-314 (2014)

24. J. Piermaria, A. Bosch, A. Pinotti, O. Yantorno, M.A. Garcia, A.G. Abraham, Kefiran films plasticized with sugars and polyols: water vapor barrier and mechanical properties in relation to their microstructure analyzed by ATR/FT-IR spectroscopy. Food Hydrocolloid. 25(5), 1261-1269 (2011)

25. I. Quijada-Garrido, V. Iglesias-González, J.M. Mazón-Arechederra, J.M. Barrales-Rienda, The role played by the interactions of small molecules with chitosan and their transition temperatures. glassforming liquids: 1,2,3-Propantriol (glycerol). Carbohydr. Polym. 68, 173-186 (2007)

26. P.G. León, S. Chillo, A. Conte, L.N. Gerschenson, M.A. Del Nobile, A.M. Rojas, Rheological characterization of deacylated/ acylated gellan films carrying L-(b)-ascorbic acid. Food Hydrocolloid. 23, 1660-1669 (2009)

27. P.P. Dhawade, R.N. Jagtap, Characterization of the glass transition temperature of chitosan and its oligomers by temperature modulated differential scanning calorimetry. Adv. Applied Sci. Res. 3(3), 1372-1382 (2012)

28. C.G.T. Neto, J.A. Giacometti, A.E. Job, F.C. Ferreira, J.L.C. Fonseca, M.R. Pereira, Thermal Analysis of Chitosan Based Networks. Carbohydr. Polym. 62, 97-103 (2005)

29. M. Mucha, A. Pawlak, Thermal analysis of chitosan and its blends. Thermochim. Acta 427, 69-76 (2005)

30. A. Domjan, J. Bajdik, K. Pintye-Hódi, Understanding of the plasticizing effects of glycerol and PEG 400 on chitosan films using solid-state NMR spectroscopy. Macromolecules 42(13), 46674673 (2009)

31. O.R. Fennema, Food Chemistry, 3rd edn. (Marcel and Dekker Inc., New York, 1996)

32. L. Slade, H. Levine, Beyond water activity: recent advances based on an alternative approach to the assessment of food quality and safety. Crit. Rev. Food Sci. Nutr. 30, 115-360 (1991)

33. I. Yakimets, S.S. Paes, N. Wellner, A.C. Smith, R.H. Wilson, J.R. Mitchell, Effect of water content on the structural reorganization and elastic properties of biopolymer films: a comparative study. Biomacromolecules 8, 1710-1722 (2007)

34. M. Laporta, M. Pegoraro, L. Zanderighi, Perfluorosulfonated membrane (Nafion) FT-IR study of the state of water with increasing humidity. Phys. Chem. Chem. Phys. 1, 4619-4628 (1999)

35. H. Wilhelm, M. Sierakowski, G. Souza, F. Wypych, Starch films reinforced with mineral clay. Carbohydr. Polym. 52, 101-110 (2003)

36. M. Roussenova, M.A. Alam, PALS: A unique probe for the molecular organisation of biopolymer matrices. 16th International Conference on Positron Annihilation (ICPA-16). J. Phys. Conf. Ser. 443, 012-044 (2013)

37. M. Roussenova, M. Murith, A. Alam, J. Ubbink, Plasticization, antiplasticization, and molecular packing in amorphous carbohydrate-glycerol matrices. Biomacromolecules 11, 3237$3247(2010)$

38. K. Pintye-Hódi, G.I. Regdon Jr., K.K. Eros Süvegh, T. Marek, I. Kéry, R. Zelkó, Metolose-PEG interaction as seen by positron annihilation spectroscopy. Int. J. Pharm. 313, 66-71 (2006) 